\title{
Model of Bamboo Strip Notch Reinforced Concrete Beams On The Flexural Capacity
}

\author{
Agus Setiya Budi ${ }^{1, *}$, and Agus P Rahmadi ${ }^{2}$ \\ ${ }^{1}$ Lecturer, Department of Civil Engineering, Universitas Sebelas Maret, Indonesia \\ ${ }^{2}$ Lecturer, Department of Civil Engineering, Universitas Sebelas Maret, Indonesia
}

\begin{abstract}
There are many various species of bamboo trees in Indonesia, one of which is Petung bamboo (Dendrocalamus Asper). Bamboo is one of the potential material as a substitute for steel reinforcement. This paper will discuss the model of bamboo reinforcement to increase the flexural capacity of concrete beams. The use of the notch is expected to increase the bonding effects and minimize slip effects. This study used laboratory experimental method. Bamboo strips are processed and formed with the notches of the form $\mathrm{V}$ with the distance between the notch are 2, 3, 4, 5, 6 and $7 \mathrm{~cm}$. Static loading is done with third point loading system (ASTM C78). The test results show that, the average flexural capacity on the specimens of concrete beams with Petung bamboo strip notch as reinforcement on the distance between notch $2,3,4,5,6$ and $7 \mathrm{~cm}$ respectively are $0.536,0.528,0.432$, $0.403,0.424,0.366 \mathrm{tm}$.
\end{abstract}

\section{Introduction}

It is a fact that the construction industry is the main consumer of energy and materials in most countries. In consequence of the consumers choosing industrialized products, among other effects, activities are suppressed in rural areas or even in small towns, and renewable materials are wasted and causing permanent pollution. In this sense, it becomes obvious that ecological materials satisfy such fundamental requirements, making use of agricultural byproducts such as rice husk, coconut fibres, sisal and bamboo and therefore minimizing energy consumption, conserving non-renewable natural resources, reducing pollution and maintaining a healthy environment [1].

Bamboo is a category of plants that are easy to grow and easy to find especially in Asia. Bamboo has several advantages, one of them is on the side of bamboo fiber which has a high enough tensile strength, especially on the outer bamboo fiber side or on the bamboo skin. Research results by [2], the bamboo is one of the suitable replacements of reinforcing bar in concrete for low cost constructions. Bamboo is natural, cheap, widely available and most importantly strong in both tension and compression.

There are many various species of bamboo trees in Indonesia, one of which is Petung (Dendrocalamus Asper). According to [3] bamboo could be used as a substitute for steel

" Corresponding author: asb0909@yahoo.co.id 
reinforcement. This suggests that bamboo can be used to replace mild steel for low cost structural construction.

But the use of bamboo as a substitute for steel directly on the construction is still encountered some obstacles, one of them is the slip effect that occurs between the concrete and bamboo. Therefore, to reduce the slip effect between bamboo and concrete, this paper will discuss the model of bamboo reinforcement to increase the flexural capacity of concrete beams in a simple construction.

\section{Material properties}

\subsection{Bamboo}

Just like timber, bamboo is vulnerable to environmental degradation and attacks by insects and moulds. Its durability varies with the type of species, age, conservation condition, treatment and curing. Curing should be initiated when bamboo is being cut in the bamboo grove. There is a strong relation between insect attacks and the levels of starch plus humidity content of bamboo culm. In order to reduce the starch content, bamboo receives a variety of treatments including curing on the spot, immersion, heating or smoke [4].

The bamboos with the following characteristics were selected: 1). Only bamboos showed a pronounced brown color were used to ensure that the plant is matured and at least three years old; 2). Selection of the longest large diameter culms available was made while as far as possible, long straight bamboos without any deformations and cracks were selected. Bamboos used are free of any decay, fungus growth or holes due to white ants; 3 ). The bamboos were not cut under wet condition because the culms are generally weaker due to increased fiber moisture content [5].

The difficulty associated with durability of raw bamboo is that it absorbs water from the surrounding environment through fine cracks in concrete. This results in swelling of the bamboo. Swelling occurs when there is sufficient time for water to reach the bamboo before the concrete cures. It is then absorbed by the bamboo microstructure, which induces an expansion of the bamboo reinforcement and promotes internal local stress in the concrete surrounding the bamboo. Over a long period of time, the consequences are brittle splitting failure in concrete can result in sudden collapse [6].

In this research using bamboo Petung species (Dendrocalamus Asper), with bamboo above the age of 3 years. Characteristic of this bamboo has a diameter of $20-30 \mathrm{~cm}$, bamboo thickness about $1.5-3 \mathrm{~cm}$ and height 10-20 m. Part of culms used is part of a bamboo rod 5 $\mathrm{m}$, which cut 1.5 meters from the base of a tree. This bamboo was obtained from the Banyu Urip village, District Klego, Boyolali, Central Java, Indonesia. The average value of the water content bamboo is $14.67 \%$ and the average density is $1.09 \mathrm{~g} / \mathrm{cm} 3$. The average tensile strength parallel to the fiber (with node of bamboo) is $223.89 \mathrm{MPa}$.

\subsection{Bamboo strip notch model}

According to [7], due to remarkable difference between steel shear strength and longitudinal shear strength of bamboo (7.45 $\mathrm{MPa}$ for dry and 4.12 $\mathrm{MPa}$ for wet bamboo), all of assumptions and calculations are different. In a steel deformed bar, the root connection of the dent (b) regarding to distance between dents (c) is small, see Fig 1. 


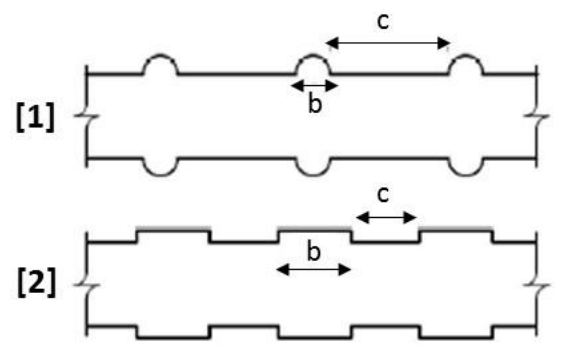

Fig.1. (1) Shape of a steel deformed bar (2) Shape of bamboo corrugated strips.

It can be justified because of remarkable difference between steel and concrete shear strength. As the bamboo longitudinal shear strength and concrete shear strength are close together then the length of dent (b) would be closer to distance between dents (c). Because of proper bamboo workability, it can be easily filed and corrugated in field. By using this method for improving the bond, the necessity of using other chemical coating for increasing the bond will be lessened [7].

See Fig. 2, it was presented the dimension strip notch V model of bamboo reinforcement bar types studied. The selected bamboo strips is then dried for over 15 days, then cut and separated into bamboo strips of $5 \times 20 \times 1650 \mathrm{~mm}$ and then notch at any distance of 2, 3, 4, 5, 6 and $7 \mathrm{~cm}$.
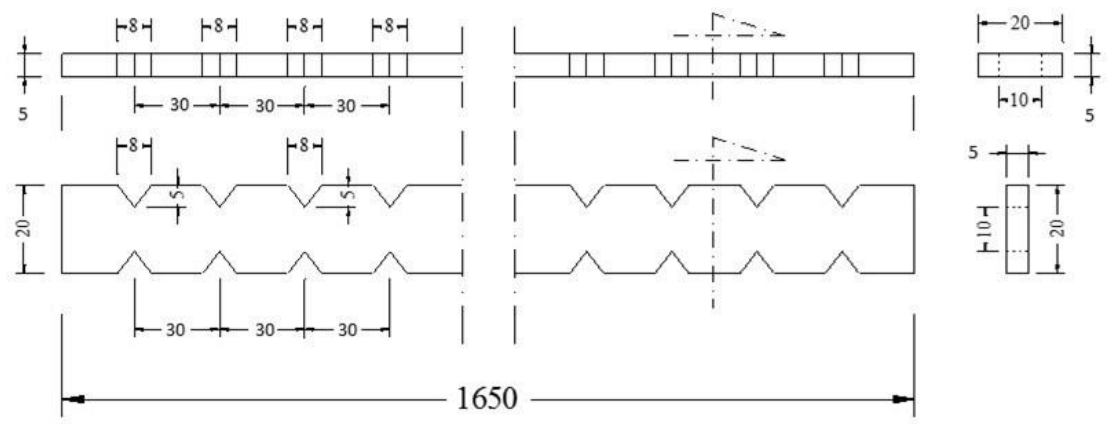

Fig.2. Detail dimension of bamboo strips notch V model (example for distance $3 \mathrm{~cm}$ ).

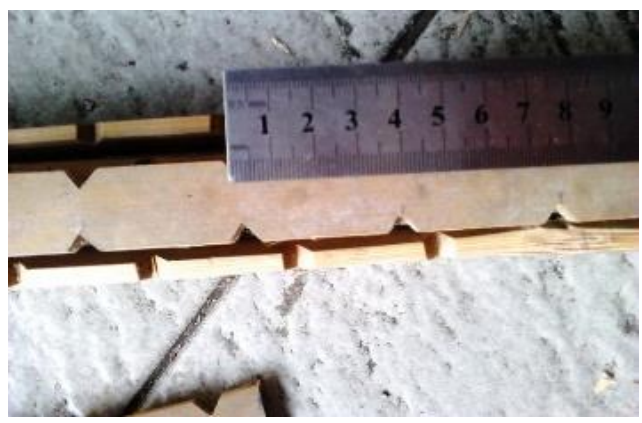

Fig.3. Examples of completed bamboo notch V model.

For comparison, in this experiment using a steel round bars $\varnothing 8 \mathrm{~mm}$ as reinforcement. The tensile test results show that, maximum average tensile strength is $639.91 \mathrm{MPa}$ and yield strength average of steel round bars as reinforcement is $487.87 \mathrm{MPa}$. The type of cement used is Portland Pozzolan Cement (PPC) which conform with Indonesian National Standard (SNI 15-0302-94). 
Based on experimental test results in the laboratory, the value of concrete compressive strength was taken based on the test of 3 cylindrical specimens with the size of $15 \times 30 \mathrm{~cm}$ and has 30 days of age. The average value of the compressive strength of the concrete is 18.29 MPa with slump value is $11.5 \mathrm{~cm}$.

\section{Testing procedure}

The size of the test beam specimen used in this research is $11 \times 15 \times 170 \mathrm{~cm}$. Detail of beam size and reinforcement placement are presented in Fig.4.
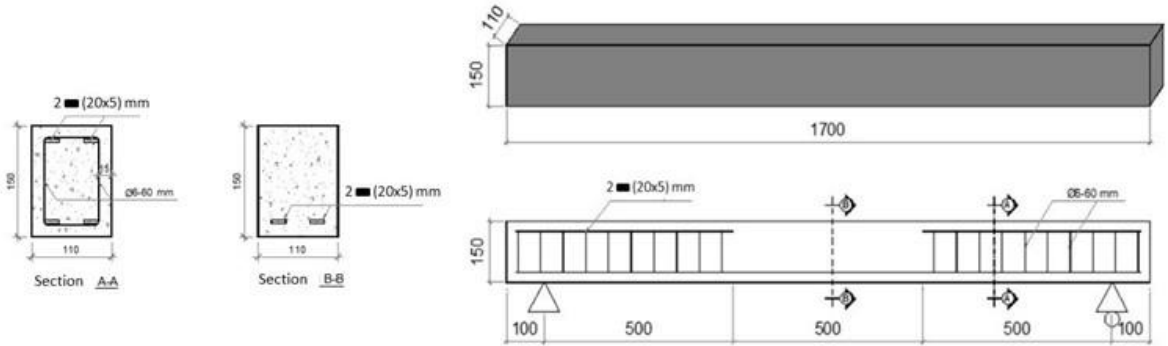

Fig.4. Position of the reinforcement on the cross section of the concrete beam.

The number of concrete blocks used in this experiment is 21 pieces. Which consists of beams for each variation of notch amounted to $6 \times 3$ pieces of beam, and 3 pieces of reinforced concrete beams of steel (Ø8mm) as a comparison. Each specimen beams is subjected to static loading in accordance with third point loading system standard (ASTM C78). The loading setting in the flexural concrete beam test experiment can be seen in Fig.5.

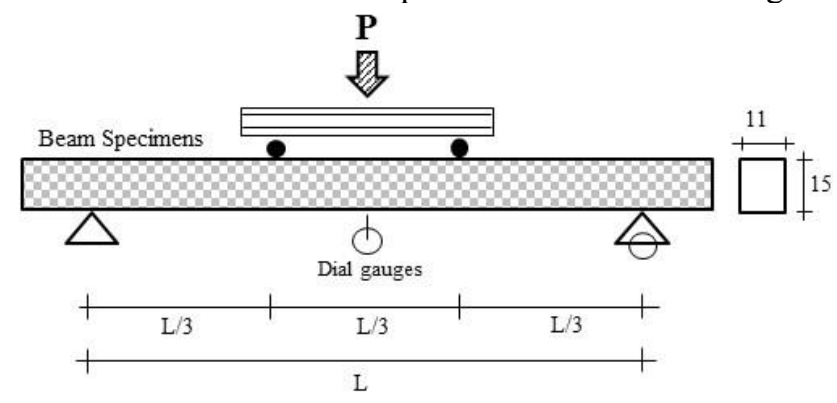

Fig.5. Loading settings on the beam

\section{Experimental and analitycal flexural moment}

Based on the loading setting, the loading distribution that occurs on the test beam specimen can be seen in Fig.6. 


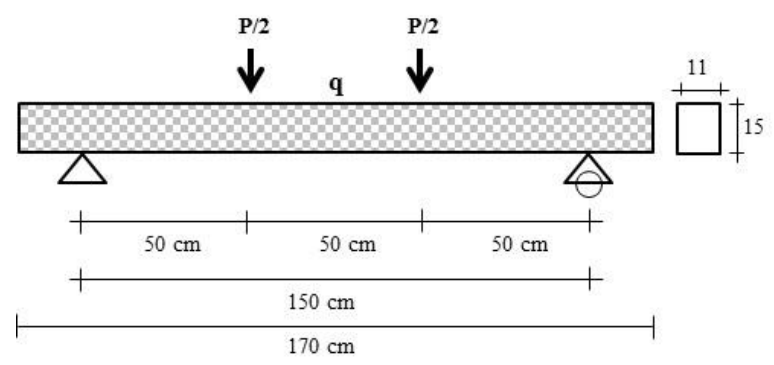

Fig.6. Loading distribution.

The static loading is carried out on the test beam specimen until the maximum load is reached and the beam collapses. The deflection occurring in the dial gauge is recorded at an increased load interval of $50 \mathrm{~kg}$. The experimental flexural moment value can be calculated based on the maximum load data and its own weight of the beam, by the static equilibrium equation of the moment, which is presented in Eq.1.

$$
M_{\max }=\left(R_{A v} \cdot L / 2\right)-\left(q L^{2} /(6.228)\right)-(P L / 12)
$$

Based on the data properties of the test beam material and the cross-sectional data, analytical ultimate moment can be calculated using a simplified stress block at the ultimate limit. Stress block diagram on the concrete beam section due to flexural forces presented in Fig.7.

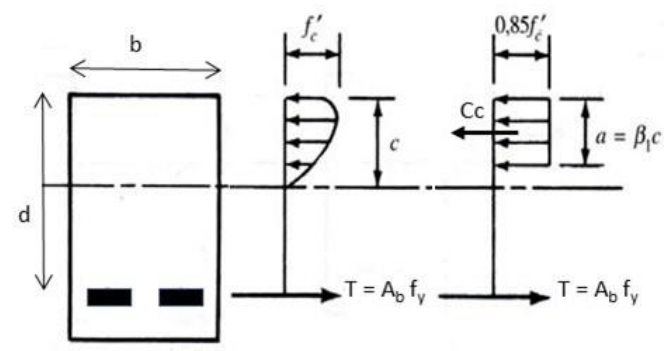

Fig.7. Stress block at the ultimate limit due to flexural forces

Analytical ultimate moment can be calculated based on simplified stress block, with equation below [8].

$$
\begin{aligned}
& \text { Tensile force }=\text { Compressive force } \\
& \qquad \begin{array}{c}
a=A_{b} f_{y} /\left(0.85 f_{c}{ }^{\prime} b\right) \\
M_{u}=\left(A_{s} f_{y}\right)(d-a / 2)
\end{array}
\end{aligned}
$$

\section{Result and discussions}

Based on the results of the test experiments on a number of specimens of concrete beams with bamboo and steel reinforcement, the following is shown in Fig.8 and Fig.9, presented a relationship diagram of load and deflection due to loading until the test specimen collapses. 


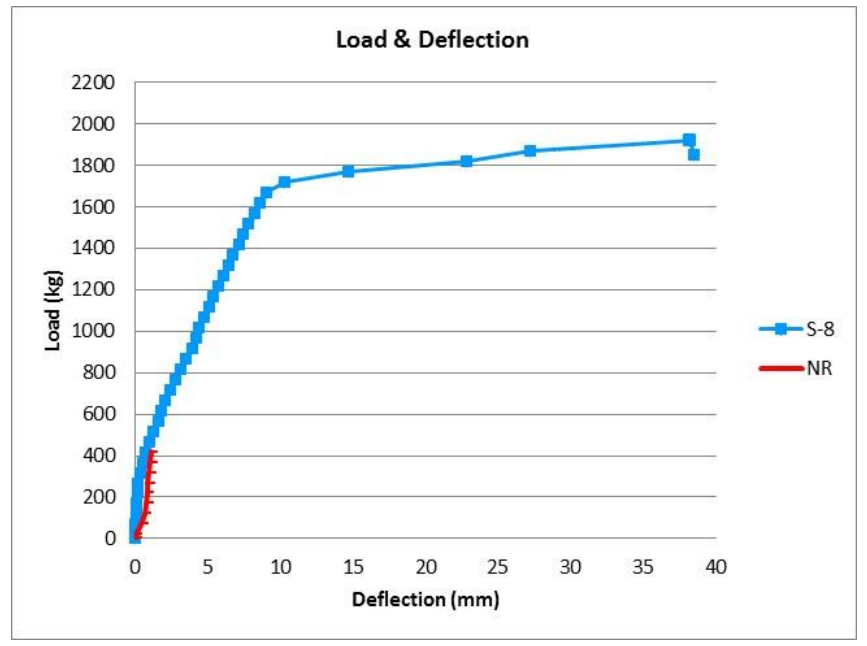

Fig.8. Load and deflection characteristics diagram on steel reinforcement and no reinforcement

Load and deflection characteristics diagram of steel reinforced concrete beam specimens and on bamboo reinforcement specimens, with a spacing between notch of 2, 3, 4, 5, 6, $7 \mathrm{~cm}$, respectively shown in Figure 9.

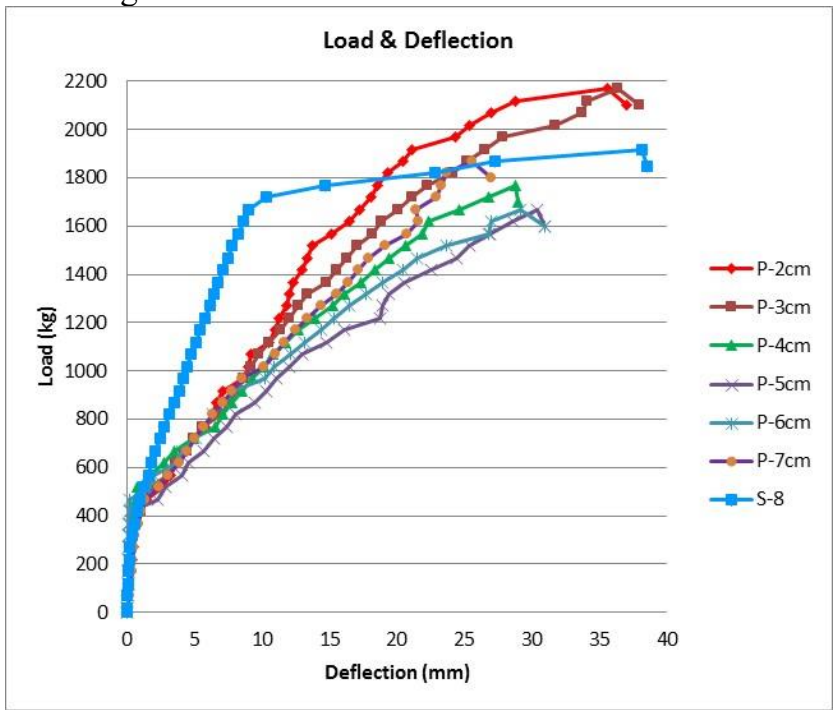

Fig.9. Load and deflection characteristics diagram on bamboo and steel as reinforcement

Note :

$\mathrm{P}-2 \mathrm{~cm}$, etc $=$ concrete beam containing bamboo strips notch at distance $2 \mathrm{~cm}$, etc

S-8 $=$ concrete beam containing steel round bar $\varnothing 8 \mathrm{~mm}$

$\mathrm{NR}=$ concrete beam no reinforcement

According to the Eq. 1, can be calculated the average value of flexural moment experiment for bamboo strip notch at distance $2,3,4,5,6$ and $7 \mathrm{~cm}$ respectively are $0.536,0.528,0.432$, $0.403,0.424,0.366 \mathrm{tm}$. And then, the value of average flexural moment experiment for steel round bar with $\varnothing 8 \mathrm{~mm}$ is $0.516 \mathrm{tm}$ and the value of average flexural moment experiment on concrete beam without reinforcement is $0.11 \mathrm{tm}$. 
According to the Eq.4, can be calculated the analytical ultimate moment for each of the beam specimens. The average value of analytical ultimate moments for steel bar as reinforcement is $0.506 \mathrm{tm}$ and for bamboo strips notch is $0.269 \mathrm{tm}$.

Below on Fig. 10 is presented a diagram the average value of the experimental flexural moment and analytical ultimate moments that occur on concrete beams specimens.

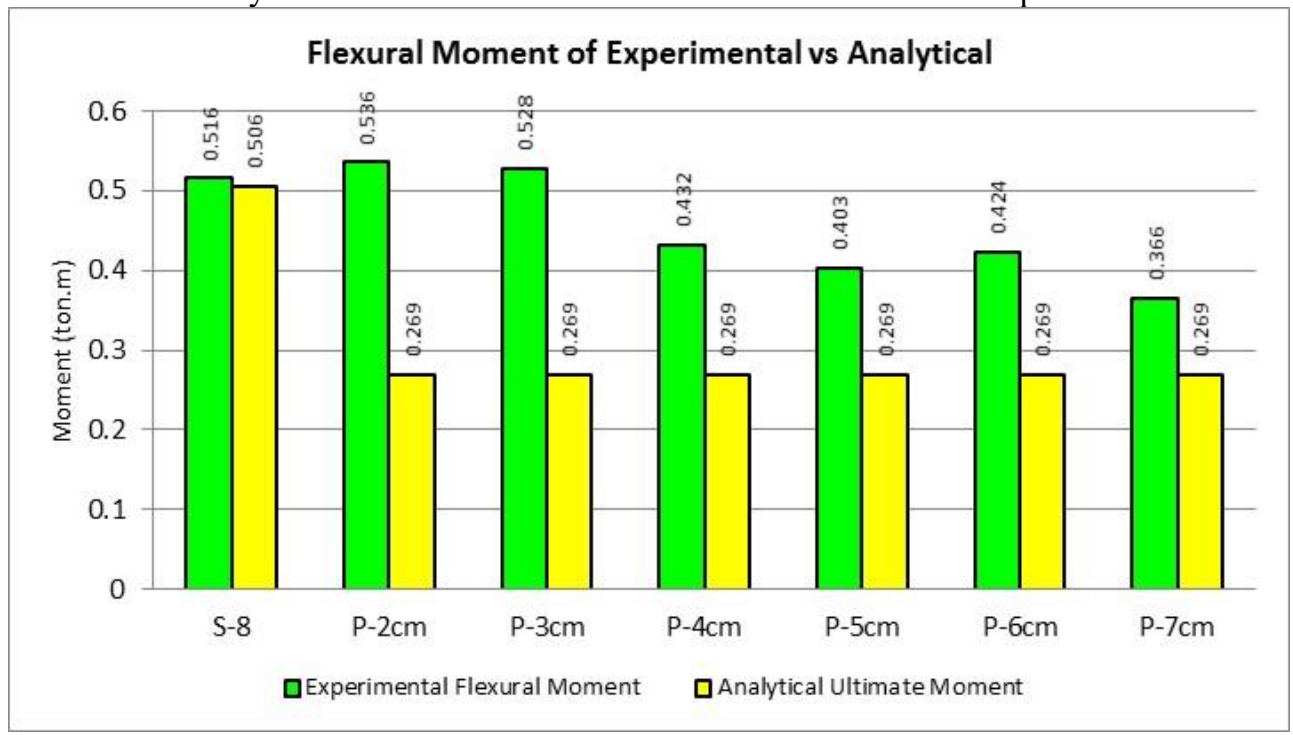

Fig.10. Flexural moment experimental vs analytical ultimate moment

Based on Fig.10, it is shown that the experimental moments tends to increase with the shorter of the distance between the notch of the bamboo strip in the tensile area.

\section{Conclusions}

Experimental results show that the average flexural capacity on the specimens of concrete beams with Petung bamboo strip notch as reinforcement on the distance between notch 2, 3, $4,5,6$ and $7 \mathrm{~cm}$ respectively are $0.536,0.528,0.432,0.403,0.424,0.366 \mathrm{tm}$. This shows that the notch model $\mathrm{V}$ can increase the value of flexural capacity and the smaller the distance between the notches will increase the value of flexural capacity.

The author would like to thank the LPPM UNS for the financial support that has been given to this experimental study.

\section{References}

1. K. Ghavami, Cem. \& Conc. Comp. Elsev. 27, 637-649 (2005)

2. M. M. Rahman, M. H. Rashid and M. A. Hossain, IJET-IJENS. 11, 04 (2011)

3. H. Sakaray, N. V. Togati and I. V. R. Reddy, IJERA. 2, 077-083 (2012)

4. K. Ghavami, Cem. Conc. Comp. Elsev. 17, 281-888 (1995)

5. M. A. Salau, I, Adegbite and E. Ikponmwosa, Jour. Sust. Dev. 5, 2, 133-143 (2012)

6. A. Javadian, Const. Build. Mat. Elsev. 122, 110-117 (2016)

7. A. Azadeh, H. H. Kazemi, KEM. 600, 69-77 (2014)

8. A.S. Budi, E. Rismunarsi, Sunaryo, AMM. 845, 208-213 (2016) 